\title{
Rzeźba jako medium edukacyjne i terapeutyczne dla studentów niepełnosprawnych
}

Jedną z dziedzin ludzkiej kultury, która towarzyszy nam przez całe życie i oddziałuje na nas pod różnymi postaciami, jest sztuka, rozumiana jako wszelaka twórczość artystyczna. Kontakt z dziełem sztuki ma wyjątkowe znaczenie w zakresie doznań poznawczych i estetycznych dla każdego człowieka, w tym zwłaszcza dla osób o różnych niepełnosprawnościach. Sztuka bowiem, oprócz kształtowania wrażliwości na piękno i motywowania do samorealizacji, staje się dla osób z różnego rodzaju dysfunkcjami istotnym narzędziem integracji z otoczeniem, środowiskiem, w którym żyją ${ }^{1}$.

Artystycznym medium, które w szczególny sposób wpływa na odbiorcę, w tym zwłaszcza na odbiorcę niepełnosprawnego, jest rzeźba. Dzieło rzeźbiarskie - relief, pojedyncza figura, zespół figur bądź instalacja przestrzenna stereotypowo traktowane jest jako obiekt przeznaczony do oglądu wyłącznie wzrokowego. Tymczasem jako obiekt przestrzenny, trójwymiarowy rzeźba

1 E. Woydyłło, Psychoterapeutyczna funkcja sztuki w świecie postindustrialnym, http://www. woydyllo.pl/ (dostęp: 13.03.2014); por. J. Gernat, Terapia poprzez sztukę i jej znaczenie dla zdrowego trybu życia oraz integracji studentów niepełnosprawnych, [w:] Promocja zdrowia w chorobie i niepetnosprawności. Modele zdrowego stylu życia jako wyzwanie wspótczesnych uczelni wyższych, Gorzów Wielkopolski 2014, s. 135-140. 
248 ma cechy formalne, które możemy poznawać polisensorycznie - obok wzroku także za pomocą dotyku, węchu, a niekiedy nawet smaku czy odczuwania temperatury ${ }^{2}$. Doświadczając w ten sposób pracy rzeźbiarskiej, otrzymujemy nowy, bogatszy obraz dzieła. Co więcej, jest to artystyczne medium dostępne bezpośredniemu poznaniu przez osoby o różnych dysfunkcjach, np. niewidome i niedowidzące. Doświadczanie przez nich rzeźby różnymi zmysłami, m.in. dotykiem, w szczególny sposób umożliwia skuteczną kompensację dysfunkcyjnego zmysłu wzroku. Wspomnieć należy również o terapeutycznych walorach polisensorycznego „odkrywania” rzeźb wszelkiego typu, które nadają nowy wymiar przeżyciu estetycznemu, zarówno osób niepełnosprawnych, jak i pełnosprawnych. Wszystkie te elementy pozwalają uznać dzieło rzeźbiarskie za skuteczne narzędzie wsparcia studentów niepełnosprawnych w edukacji i integracji z otoczeniem.

W niniejszej szkicu podjęta zostanie próba rozpatrzenia problemu dzieła rzeźbiarskiego jako medium polisensorycznego możliwego do wykorzystania w celach arteterapeutycznych. Możliwości takie dostrzegły jako pierwsze muzea, tradycyjne świątynie sztuki, które wykorzystując doświadczenie polisensoryczne, coraz częściej udostępniają osobom dysfunkcyjnym swoje zbiory rzeźby. Wśród przykładów tego rodzaju są pionierskie działania paryskiego Luwru, który w 1995 roku otworzył Galerię Dotyku, złożoną z odlewów i kopii wybranych rzeźb ze swojej kolekcji, przeznaczonych do poznawania dotykowego. Powstała z myślą o gościach niewidomych galeria, sukcesywnie wzbogacana o nowe eksponaty prezentowane w ramach różnorodnych ścieżek tematycznych (np. dotyczące starożytności, symboli władzy, zwierząt), zyskała ogromną popularność zarówno wśród odbiorców niepełnosprawnych, jak i pełnosprawnych, rozwijając wśród publiczności zupełnie nowe, sensoryczne podejście do dzieła rzeźbiarskiego, co ma z kolei wpływ na integrację różnych grup zwiedzających z dysfunkcjami oraz pozostałych ${ }^{3}$.

2 Zagadnienie doświadczenia polisensorycznego oraz integracji sensorycznej szerzej omawia M. Karga, Co to jest SI, http://www.integracjasensoryczna.com.pl/pl/Co-to-jest-SI (dostęp: 18.06.2015), por. J. Gernat, Doświadczenie polisensoryczne i jego znaczenie w edukacji artystycznej osób niepełnosprawnych, [w:] Edukacja i niepełnosprawność w wyobraźni socjopedagogicznej, Gorzów Wielkopolski 2013, s. 111-121.

3 M. Szeląg, Pozwalamy dotykać! Muzea wobec potrzeb różnorodnej publiczności, [w:] 5 zmystów. Audiodeskrypcja, pod red. E. Drążkowskiej i M. Szeląga, Poznań 2011, s. 20-22; por. Ch. Cuny, Renouvellement de la Galerie tactile: „sculpter le corps”. Louvre. Communiqué de presse avril 2014, http://www.louvre.fr/sites/default/files/medias/medias_fichiers/ 
Inicjatywy pomyślanego $\mathrm{w}$ ten sposób polisensorycznego poznawania dzieł sztuki nie ograniczają się wyłącznie do instytucji tak znanych jak Luwr. Pośród wielu innych przykładów wymienić można program Metropolitan Museum of Manila na Filipinach, zatytułowany Dotknij wizji artysty. $\mathrm{W}$ ramach tego programu na galeriach wyeksponowane zostały oryginalne dzieła sztuki dostępne poznaniu dotykowemu, zaś te, których dotknąć nie można, wyposażono w ich haptyczne repliki. Ekspozycjom towarzyszą ponadto podpisy w brajlu oraz audiodeskrypcja prezentowanych dzieł sztuki. Jak podaje Marcin Szeląg, dzięki inicjatywie muzeum, uzupełnionej warsztatami oraz specjalnymi dotykowymi książkami, w programie wzięło udział 3,7 miliona niewidomych lub niedowidzących Filipińczyków ${ }^{4}$.

Coraz więcej tego typu działań podejmują muzea w Polsce, wśród których wymienić możemy np. inicjatywę Muzeum Narodowego w Krakowie, w którym grupom niewidomych udostępniono zarówno kopie poszczególnych rzeźb i detali architektonicznych (kopie arcydzieł rzeźby gotyckiej oraz wystawa „Kraków na wyciągnięcie ręki” w Pałacu Biskupa Erazma Ciołka), jak też niektóre prace oryginalne, m.in. dzieła rzeźby młodopolskiej oraz kubicznej z okresu międzywojennego w Gmachu Głównym ${ }^{5}$. Na szczególną uwagę zasługuje inicjatywa Muzeum Regionalnego w Stalowej Woli, w którym pod kierunkiem Jarosława Pajka z Centrum Rzeźby Polskiej w Orońsku powstała w 2008 roku Galeria przez dotyk - kamienny zespół rzeźb wykonany przez rzeźbiarzy polskich i ukraińskich specjalnie z myślą o poznawaniu ich dotykiem m.in. przez niewidomych. Stała plenerowa ekspozycja Galerii przez dotyk, w odróżnieniu od Galerii Dotyku w Luwrze, pozwala zwiedzającym, w pierwszym rzędzie osobom z dysfunkcją wzroku, poznawać dotykiem oryginalne dzieło sztuki, po raz pierwszy na tak dużą skalę̧. Forma wielu $\mathrm{z}$ rzeźb zaprojektowana została $\mathrm{w}$ taki sposób, aby zachęcić odbiorcę do taktylnego doświadczania dzieła, np. poprzez przyłożenie dłoni

fichiers/pdf/louvre-cp-galerie-tactile.pdf (dostęp: 04.07.2014); http://www.louvre.fr/ accessibilite (dostęp: 25.05.2013).

4 M. Szeląg, Pozwalamy dotykać!..., dz. cyt., s. 22.

5 Muzeum Narodowe w Krakowie - informacja dotycząca działań na rzecz osób niepełnosprawnych w latach 2008-2012, mps niepubl., nlb, udostępniony autorowi przez p. M. Dylewską z Działu Edukacji Muzeum Narodowego w Krakowie.

6 Na temat Galerii przez dotyk Muzeum Regionalnego w Stalowej Woli zob. m.in.: http:// muzeum. stalowawola.pl/pl/wystawy/wystawy-stale/item/153-gallery-by-touch (dostęp: 04.07.2014); Galeria przez dotyk. Edycja II. Katalog poplenerowej wystawy rzeźby. Muzeum Regionalne w Stalowej Woli, pod red. M. Młynarskiego i A. Garbacz, Stalowa Wola 2008, passim. 
250 do odpowiadającej jej kształtem wnęki w jednej z figur. Sprzyja temu również kamienna materia rzeźb, która oferuje zwiedzającym różnorodne doznania taktylne, w szczególności pobudzając wyobraźnię osoby niewidzącej obiektu .

Rozwiązaniom ekspozycyjnym wielu muzeów towarzyszą programy edukacyjne skierowane do osób niepełnosprawnych, polegające na wykonywaniu różnych działań artystycznych bądź uczeniu się historii sztuki w oparciu o polisensoryczne doświadczanie rzeźb. Wśród coraz liczniejszych tego typu programów wymienić możemy warsztaty i zajęcia towarzyszące przywołanej stalowowolskiej Galerii przez dotyk, przeznaczone dla różnych grup odbiorców z różnymi niepełnosprawnościami - obok wzrokowych także z innymi, m.in. dysfunkcjami intelektualnymi, bądź inicjatywy podejmowane przez Muzeum Narodowe w Krakowie. W większości wypadków punktem wyjścia tych warsztatów jest doświadczanie różnymi zmysłami dzieła rzeźbiarskiego (nierzadko dopełnione innymi artefaktami dotykowymi), które jest podstawą dalszej aktywności uczestników, m.in. różnorakich działań plastycznych ${ }^{8}$.

Tego rodzaju zastosowanie sztuki nie musi ograniczać się wyłącznie do programów muzealnych, bowiem zdecydowana większość dzieł rzeźbiarskich sztuki dawnej i współczesnej daje szerokie możliwości odbioru polisensorycznego również poza muzeum, np. rzeźba plenerowa, w przestrzeni publicznej czy w zabytkowych wnętrzach (np. w kościołach). Spotykana niemal na co dzień przez każdego z nas, rzeźba okazuje się medium szczególnym, za pomocą którego studenci niepełnosprawni, wśród nich zwłaszcza niewidzący, na różnych płaszczyznach mogą uczyć się otaczającej ich rzeczywistości, a zarazem w wyjątkowy sposób doświadczać artystycznych walorów dzieł plastyki, co w wielu wypadkach ma również wielki wymiar terapeutyczny. Spróbujmy zatem przyjrzeć się, jak dzieła rzeźbiarskie z różnych epok mogą działać na odbiorcę.

7 J. Pajek, Kamienne wtajemniczenie, [w:] Galeria przez dotyk..., dz. cyt., s. 13; W. Gogol, Świat poprzez sztukę dotyku staje się bardziej dostępny, [w:] Galeria przez dotyk..., dz. cyt., s. 20-22.

8 Na temat edukacji muzealnej niepełnosprawnych prowadzonej przez muzea w Stalowej Woli i Krakowie zob. m.in. T. Cwalina, A. Szlązak, Warsztaty dla osób niewidomych i niedowidzących, [w:] Pakiet edukacyjny Dostępne Muzeum, red. E. Lisek, A. Szlązak, Stalowa Wola 2007, nlb.; Muzeum Narodowe w Krakowie - informacja..., dz. cyt., passim. Zagadnienie programów edukacyjnych również w innych polskich ośrodkach muzealnych szerzej omówione w: J. Gernat, Edukacja muzealna osób niepełnosprawnych i możliwość jej zastosowania w nauczaniu akademickim, [w:] Globalno-lokalne wyzwania uczelni wyższych zwiazzane z niepełnosprawnością, red. B. Orłowska, P. Prüfer, Gorzów Wielkopolski 2012, s. 137-146; J. Gernat, Doświadczenie polisensoryczne..., dz. cyt., s. 111-121. 
Zanim podejmiemy się analizy wybranych rzeźb, należy zwrócić uwagę, że badania z wykorzystaniem różnych zmysłów, również dotyku czy zapachu, prowadzone są przez historyków sztuki i konserwatorów w celu nie tylko bliższego określenia formy artystycznej i klasyfikacji stylowej danej figury, ale również ustalenia jej parametrów technicznych: pomiaru wielkości, poznania materiału, $\mathrm{z}$ którego rzeźba powstała - jego rodzaju, struktury i faktury - czy też zgłębienia wiedzy na temat techniki rzeźbiarskiej twórcy. Tego rodzaju studia nie muszą ograniczać się do wąskiego kręgu specjalistów bądź studentów kierunków artystycznych, ponieważ wykazują one przydatność poznawczą i edukacyjną również dla zróżnicowanych grup odbiorców, w tym studentów niepełnosprawnych. Chociaż wiele dzieł sztuki jest niedostępnych do poznania multisensorycznego, możliwości takie oferują precyzyjne kopie oryginalnych dzieł. Wykonane z trwalszych materiałów (niekiedy imitujących autentyczną materię), dotykowo dają nam stosunkowo wierne wyobrażenie artystycznej formy oryginału. W niektórych wypadkach możliwe jest uzyskanie jeszcze większego poczucia kontaktu odbiorcy $\mathrm{z}$ autentycznym dziełem poprzez udostępnienie mniej wartościowych dzieł sztuki w przybliżeniu powielających formę oryginału, np. XIX-wiecznych imitacji rzeźb gotyckich, jak to ma miejsce w wypadku ścieżki zwiedzania dla niepełnosprawnych wzrokowo w krakowskim Muzeum Narodowym?

Przechodząc do analizy konkretnych dzieł, nasze badanie rozpoczniemy od drewnianej rzeźby barokowej. Barokowe figury ze swoim bogactwem rozwiązań formalnych, takich jak skomplikowana i dynamiczna często kompozycja, zróżnicowane układy draperii strojów czy ekspresja fizjonomii, wydają się w szczególny sposób predestynowane do poznania multisensorycznego. Za przykład takiej rzeźby niech posłuży nam późnobarokowa figura Chrystusa Zmartwychwstałego (il. 1), pochodząca z kościoła parafialnego w Lądku-Zdroju w Kotlinie Kłodzkiej, wykonana w latach 1735-1740 przez warsztat Michała Klahra Starszego (1693-1742) - najwybitniejszego rzeźbiarza barokowego Kłodzczyzny, należącego do czołowych przedstawicieli rzeźby okresu baroku na Śląsku ${ }^{10}$. Rzeźbiarska twórczość Klahra odznacza się wieloma indywidualnymi rysami i ekspresją wyrazu, w niejednym wypadku zadziwiającą również współczesnego odbiorcę. Decydują o tym

9 Muzeum Narodowe w Krakowie - informacja..., dz. cyt., passim.

10 Na temat plastyki Michała Klahra St. zob. m.in. K. Kalinowski, Rzeźba barokowa na Śląsku, Warszawa 1986, s. 186-194; R. Nowak, Michat Klahr Starszy i jego theatrum sacrum, Kłodzko 1992, s. 10-42; Teatr i mistyka. Rzeźba barokowa pomiędzy Zachodem a Wschodem, pod red. K. Kalinowskiego, Poznań 1993, s. I.23-I.45. 
252 m.in. wyrafinowane układy kompozycyjne z charakterystycznym esowatym układem sylwetki, idealizowana, muskularna anatomia, rzeźbiona miękko, w bardzo plastyczny sposób, rozbudowany rysunek mięsistej i przestrzennie potraktowanej draperii, naturalizm, a zarazem ekspresja twarzy czy bujnych włosów - elementy, które silnie pobudzają wyobraźnię nas, odbiorców, zachęcając wręcz do „odkrywania” ich nie tylko wzrokiem, ale również dotykiem, a niekiedy innymi zmysłami. Wszystkie te cechy obecne są w lądeckiej figurze Chrystusa Zmartwychwstałego (analizowanej m.in. dotykowo przez piszącego te słowa).

Wysoka na $90 \mathrm{~cm}$ polichromowana rzeźba ukazuje stojącą postać Chrystusa, depczącego ugiętą prawą nogą czaszkę z wężem oraz z ręką uniesioną w geście błogosławieństwa. Figura jest pełnoplastyczna i dostępna do oglądu ze wszystkich stron, co dodatkowo zachęca do różnokierunkowego, taktylnego poznawania dzieła. $Z$ różnych perspektyw przyglądać się możemy zwłaszcza dynamicznym układom kompozycyjnym sylwetki Jezusa ukazanego w triumfalnej pozie, podporządkowanej kierunkom wertykalnym, a zarazem ożywionej dynamicznym skrętem ciała. Na ekspresję rzeźby wpływa przestrzenność i rozczłonkowanie kompozycji, co możemy odkryć nie tylko wzrokiem, ale i dotykiem, rozpoznając tą drogą detale, począwszy od imitującego skałę postumentu figury poprzez czaszkę oplecioną wężem, najbardziej przestrzenne elementy postaci, takie jak detale anatomii i odstające fragmenty szaty, aż po głowę i drzewce z chorągwią. Zmysł dotyku okazuje się szczególnie przydatny w badaniu szczegółów anatomii, która jest prawie w całości odsłonięta. Pod palcami wyczuwalny jest realizm wiernie oddanych detali, takich jak silnie podkreślone żebra, muskulatura, ścięgna, palce, a także rany po gwoździach wraz z raną w prawym boku w formie drobnej księżycowatej wnęki, do której nieomal można włożyć palec. Możliwe jest również tą drogą poznanie ekspresyjnej fizjonomii Zmartwychwstałego, „dotykalnej” w bardzo plastycznym wykonaniu twarzy (np. zapadłych policzków), jak i włosów w formie bujnych, pofalowanych loków, ułożonych w charakterystyczny kosmyk opadający na bark. Za pomocą podobnych taktylnych zabiegów badawczych możemy dokładniej rozpoznać rysunek mięsistej draperii szat Chrystusa, skoncentrowanej wokół bioder i opadającej kaskadowo na lewą nogę, wyżej zaś przerzuconej przez lewe ramię na plecy. W tym wypadku dotyk ujawnia silne zmarszczenia stroju oraz głęboko wcięte fałdy zróżnicowanej wielkości, kształtu i głębi bądź płaszczyzny wypracowane miękko, a niekiedy w formie geometrycznych załamań. Miejscami fałdowanie przypomina przestrzenne, trójwymiarowe 
struktury, co dostrzegalne i dotykowo wyczuwalne jest przy lewym biodrze oraz za plecami postaci, gdzie odkrywamy, że rozwiana, silnie wywinięta i pofalowana krawędź płaszcza staje się niemal niezależną od figury bryłą.

Do procesu poznania możemy włączyć także zmysł słuchu, który okazuje się przydatny, gdy figurę w różnych miejscach delikatnie ostukujemy w celach badawczych. W ten sposób możemy zidentyfikować drewnianą strukturę rzeźby bądź ustalić jej ciężar. Równocześnie osoby niewidome lub niedowidzące za pomocą dotyku, a nawet zapachu, względnie smaku (przez polizanie), mają możliwość poznania powierzchni dzieła: w większości gładkiej, starannie wykończonej, w miejscach uszkodzeń i ubytków malatury

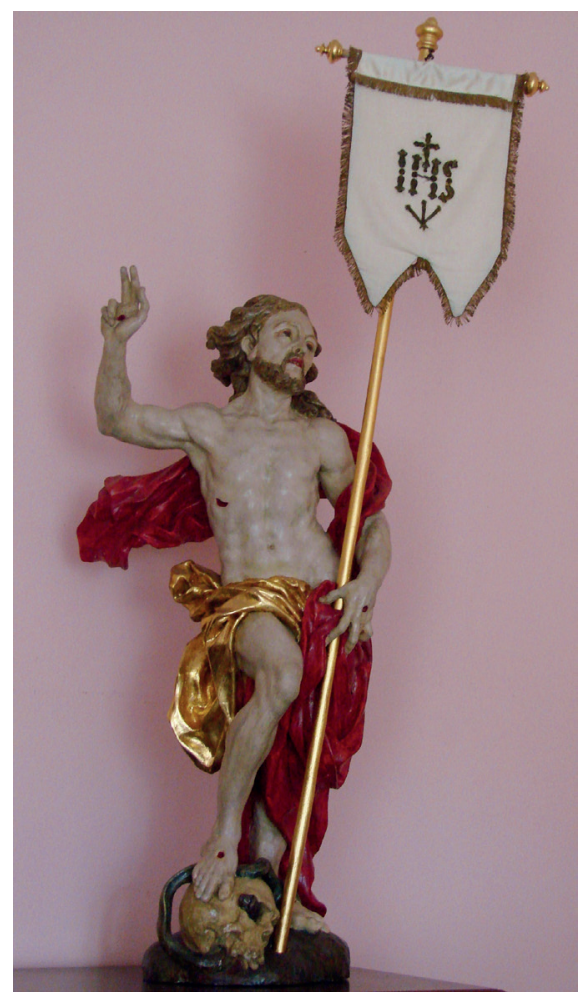

II. 1. Michał Klahr Starszy, Chrystus Zmartwychwstały, 1735-1740, Lądek-Zdrój, plebania kościoła parafialnego (fot. J. Gernat 2011) chropowatej i nierównej. Mogą ponadto wyróżnić tą drogą barwy polichromii dzięki zdolności rozróżniania kolorów o określonej gamie i temperaturze bądź zapachu ${ }^{11}$. Rzeźba Zmartwychwstałego poszerza gamę doznań fakturalnych o strukturę miękkiej tkaniny, z jakiej wykonano chorągiew Chrystusa, jej zróżnicowaną powierzchnię (uwagę zwraca przede wszystkim wyhaftowany z wypłowiałego brokatu ozdobny monogram IHS) i wieloboczny kształt, wzbogacony na krawędziach frędzlami.

Warto wspomnieć w tym miejscu, że w wypadku wielu rzeźb barokowych zmysł dotyku ułatwia identyfikację „ręki” twórcy dzieła oraz procesu jego pracy nad figurą poprzez ślady i dukty dłut, pozostawione niekiedy na powierzchni obiektu. Dotykowe badanie rzeźby pod tym kątem,

11 W. Gogol, Świat poprzez sztukę dotyku staje się bardziej dostępny, [w:] Galeria przez dotyk..., dz. cyt., s. 21-22. 


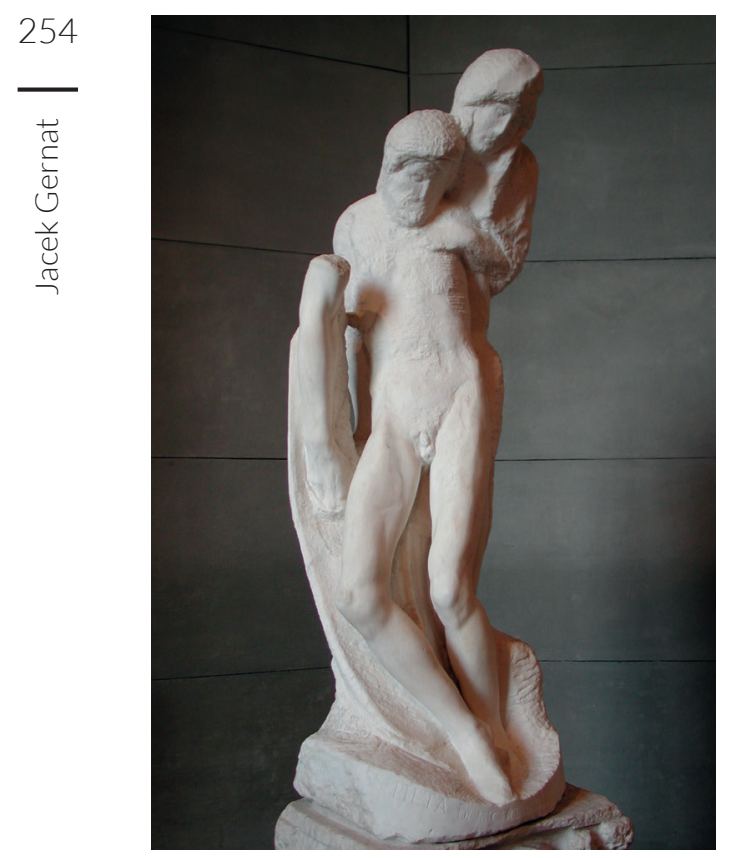

II. 2. Michał Anioł Buonarotti, Pietá Rondanini, ok. 1553-1564, Mediolan, Castello Sforzesco (fot. www.wikipedia.org) poprzedzone stosowną prezentacją narzędzi rzeźbiarskich, może być również dla osób niepełnosprawnych wzrokowo interesującym doświadczeniem edukacyjnym rozpoznawania rzeźbiarskiej techniki artysty.

Zbliżone elementy formalne, jak również ślady techniki wykonania możemy odnaleźć i podobnie „doświadczyć” ich w rzeźbie kamiennej. Ta jednak w poznaniu polisensorycznym daje nam odmienne, bardzo różnorodne doznania w kwestii materiału. Kamień bowiem, w wielu wypadkach niepokryty polichromią, ujawnia liczne poznawalne dotykowo właściwości, do których zaliczyć możemy m.in. różne rodzaje powierzchni, twardość czy zmien-

ność pod wpływem temperatury. Dodatkowymi walorami, tym razem wizualnymi, są kolorystyka, struktura mineralna, które decydują o wyrazie estetycznym figury. Jako przykład podajmy jedno z najbardziej fascynujących dzieł rzeźbiarskich w historii sztuki - renesansową Pietę Rondanini (il. 2), ostatnie ukończone dzieło Michała Anioła Buonarottiego (1475-1564), odkuwane przez artystę w marmurze kararyjskim od ok. 1553 roku niemal do śmierci. W rezultacie tak długiej pracy nad Pietą, po licznych przekształceniach pierwotnej koncepcji, powstała rzeźba wyjątkowa na tle prac innych rzeźbiarzy nowożytnych, stanowiąca swoisty testament artystyczny Buonarottiego, zapis jego wieloletnich formalnych i technicznych poszukiwań środków odpowiednich dla wyrażenia swojej indywidualnej ekspresji plastycznej ${ }^{12}$. Rzeźbiarska forma opłakiwania ma na celu ekspozycję

12 Historię powstawania rzeźby oraz jej formę artystyczną, wymowę ideową oraz aspekty techniczno-materiałowe szczegółowo omawia T. J. Żuchowski, Poskromienie materii. Nowożytne zmagania rzeźbiarzy z marmurem kararyjskim. Michał Anioł, Bernini, Canova, Poznań 2011, s. 53-123; w swoich rozważaniach na temat dzieła tu i dalej podążam za wymienionym opracowaniem. 
techniki artysty oraz fizycznych i optycznych właściwości materii, wobec której Michał Anioł miał szczególny respekt; w efekcie, jak zauważa Tadeusz J. Żuchowski, kamień i wykuta w nim Pietà „doświadczane są w jednoczesnym oglądzie"13. Tym samym czyni to pracę szczególnie interesującą dla doświadczenia polisensorycznego.

Rzeźba stanowi pozornie nieobrobiony blok marmuru, z którego „wyłaniają się” zarysy dwóch postaci - pionowa, bezwładna sylwetka Chrystusa osuwającego się w dół na ugiętych nogach oraz stojącej za nim Marii. Podtrzymuje ona ciało Syna za barki, jakby przeciwdziałając jego całkowitemu upadkowi, a zarazem przytula swoją pochyloną głowę do lewej skroni Jezusa w symbolicznym geście rozpaczy. Z lewej strony przedstawienie dopełnia oderwane od reszty precyzyjnie wyrobione ramię - ślad wcześniejszej wersji dzieła, najprawdopodobniej świadomie zachowany przez artystę. Figura ma wyrafinowaną, matematyczną kompozycję o bogatym ładunku wyrazowym i symbolicznym, zmieniającym się z różnych punktów patrzenia na rzeźbę. Jednak to nie wyszukane efekty kompozycyjne decydują o ostatecznej ekspresji dzieła, lecz materiał i jego powierzchnia, dostarczająca odbiorcy zróżnicowanych wrażeń wizualnych i dotykowych. Biały marmur kararyjski na przełamanej powierzchni ujawnia krystaliczną strukturę i połyskuje srebrzyście, zarazem doskonale nadaje się do różnicowania faktury powierzchni ${ }^{14}$, czego doświadczyć można również w arcydziele Michała Anioła. Gładką, świetlistą powierzchnię zimnej w dotyku materii możemy wyczuć pod palcami w partii precyzyjnie wykończonych i wypolerowanych łydek i kolan Chrystusa, jak również pozostawionego ramienia (widocznego m.in. z tyłu i po bokach Piety). Kontynuując eksplorację rzeźby w górę, natrafimy na fakturę zupełnie inną - nierówną, chropowatą, na której zarys postaci, zwłaszcza głów, twarzy, staje się coraz bardziej uproszczony, symboliczny - odmaterializowany, przy równoczesnej ekspozycji materialności twardego, nieobrobionego kamienia, z którego rzeźbiarz wydobywa figurę. Ów typowy dla Buonarrotiego, obudowany filozofią neoplatońską i arystoteliczną zabieg „uwalniania” idealnego kształtu figury ze skalnej materii zauważyć możemy zwłaszcza w okolicach nóg Chrystusa i samotnego ramienia, „wychodzących” z pozostawionego skalnego tła. Ponadto odnajdywane na powierzchni liczne dukty bądź wgłębienia po użytych dłutach

13 T. J. Żuchowski, Poskromienie materii..., dz. cyt., s. 301.

$14 \mathrm{Na}$ temat marmurów i związanych z nimi technik rzeźbiarskich zob. Żuchowski, Poskromienie materii..., dz. cyt., s. 13-39. 
256 zasadniczo wpływają na niezwykły wyraz estetyczny, bliski nieomal rzeźbie abstrakcyjnej. Odkrywanie tych walorów różnymi zmysłami, zwłaszcza dotykiem, możne wywoływać szeroką gamę dynamicznie się zmieniających przeżyć estetycznych, choćby zaskoczenia, szoku w momencie doświadczania gładkiej powierzchni materii, skontrastowanej po chwili z surowym lub tylko częściowo obrobionym kamieniem.

Jeszcze innych wrażeń estetycznych w polisensorycznym „oglądzie” dostarczają nam rzeźby wykonane z metalu, którymi są najczęściej odlewy, popularne zwłaszcza w rzeźbie wieku XIX i XX. Przykładem może być rzeźba Na skale z 1901 roku autorstwa Franciszka Flauma (1866-1917), należącego do ciekawszych polskich rzeźbiarzy przełomu wieków. Artysta w swojej twórczości operował repertuarem formalnym symbolizmu i secesji, będąc zarazem pod dużym wpływem sztuki słynnego Augusta Rodina. Cechy te dostrzegalne są w omawianej kreacji rzeźbiarskiej, mimo niewielkich rozmiarów oferującej szeroką gamę doznań różnymi zmysłami. Pełnoplastyczne, złożone $\mathrm{z}$ dwóch figur wielooglądowe przedstawienie ukazuje stojące na skale nagie postaci kobiety i mężczyzny zastygłych w miłosnym uścisku. W oglądzie dzieła brąz, z którego odlano rzeźbę, jest zasadniczym elementem, konstytuującym jej pełen dramatyzmu wyraz estetyczny. Od pierwszej chwili naszej obserwacji uderza bowiem świetlistość przedstawienia, budowana przez rozliczne refleksy świetlne odbijające się od nieregularnej, zróżnicowanej metalicznej powierzchni ciał i skały. Wyrafinowane układy kompozycyjne rzeźby nie muszą jednak podlegać tylko percepcji wzrokowej, ponieważ przestrzenność kompozycji, napięcia kierunkowe, położenie, kształt i zarys obu postaci wraz ze skalnym „postumentem” rozpoznać możemy także za pomocą dotyku. Podobnie jak wypadku wyżej omówionych figur pozwala on nam dodatkowo wyczuć przestrzenność dzieła, odkryć jego ażurowość, wreszcie w szczególach zbadać artystyczną formę, zróżnicowaną fakturę dzieła, typową dla rzeźby secesyjnej. Faktura rzeźby może ujawnić pod palcami badającego detale anatomii, m.in. wydatną muskulaturę młodego mężczyzny, delikatne ciało kobiety - elementy wypracowane bardzo miękko, sensualnie, w sposób nieomal zaprzeczający twardej strukturze metalu. Może ujawnić też szczegóły ukazane bardziej szkicowo, ekspresyjnie, o fakturze chropowatej, takie jak wyrażająca ekstazę twarz kobieca, fryzury (zwłaszcza długie, rozpuszczone włosy niewiasty) czy nieregularna, surowa forma skały.

Co jeszcze ważniejsze, poprzez dotyk i inne zmysły poznajemy i odczuwamy właściwości kluczowego dla tej pracy materiału, jaki stanowi brąz. 
Badanie dotykowe, ale i również słuchowe pozwala nadto ustalić twardość i spoistość, ciężar metalicznej materii rzeźby. W wypadku odlewu możemy tą drogą określić jego rodzaj: odlew pełny (monolityczny) lub odlew pusty. Odlewy z metalu są w przeważającej mierze tymi ostatnimi ${ }^{15}$. Najłatwiej jest to sprawdzić poprzez opukiwanie powierzchni figury: jednorodna materia wyda z siebie głuchy, czasem prawie niesłyszalny dźwięk, z kolei podobne potraktowanie odlewu metalowego wywoła wibracje, dźwięczny pogłos o różnej długości trwania (zależnej m.in. od wielkości obiektu i grubości metalowej powłoki), jako że wewnątrz rzeźby jest pusta przestrzeń. Tego typu efekty akustyczne pozwalają niewidomym odbiorcom na rozpoznanie techniki odlewu, a zarazem czynią z metalowego dzieła rzeźbiarskiego swoisty instrument, zależnie od aktywności poznającego oddziałujący różnymi wydawanymi odgłosami na percepcję, emocje niemal wszystkich odbiorców dzieła (również niesłyszących - poprzez wibracje sugerujące dźwięki).

Wskazane możliwości doznań płynących z tak pojętego doświadczania dzieła rzeźbiarskiego, wielokierunkowo oddziaływujących na nasze poznanie, intelekt i emocje, oferuje także rzeźba współczesna, która pomimo nowatorskich, niekonwencjonalnych środków wyrazu bądź abstrakcyjnej formy coraz częściej okazuje się dostępna poznawaniu multisensorycznemu przez osoby pełnosprawne i dysfunkcyjne. Co więcej, współcześni rzeźbiarze świadomie przełamują tradycyjne ograniczenia dotyczące oglądu i dostępności figury odbiorcy, zachęcając go do interakcji. Przykładem jest instalacja rzeźbiarska Nierozpoznani (il. 3) Magdaleny Abakanowicz, jednej z najwybitniejszych współcześnie żyjących polskich rzeźbiarek. Plenerowa praca, zlokalizowana w parku na Cytadeli w Poznaniu, jest dziełem ogólnodostępnym, możliwym do poznawania z dowolnej perspektywy, również z bliska. W istocie bezpośredni, fizyczny niemal kontakt odbiorcy z dziełem pozwala mu najpełniej dostrzec i zrozumieć jego artystyczny przekaz.

Kompozycję rzeźby tworzy 112 dwumetrowych, odlanych z żeliwa, pozbawionych głów antropomorficznych postaci, które kroczą w różnych kierunkach po żeliwnej płycie na planie wydłużonego prostokąta wkomponowanego w otaczający całość trawnik. Oparta wyłącznie o te elementy pełna

15 Odlew, [w:] Stownik terminologiczny sztuk pięknych, pod red. K. Kubalskiej-Sulkiewicz, M. Bielskiej-Łach i A. Manteuffel-Szaroty, wydanie 5, Warszawa 2006, s. 283; Forma odlewnicza, [w:] Słownik terminologiczny sztuk pięknych..., dz. cyt., 116-117. 


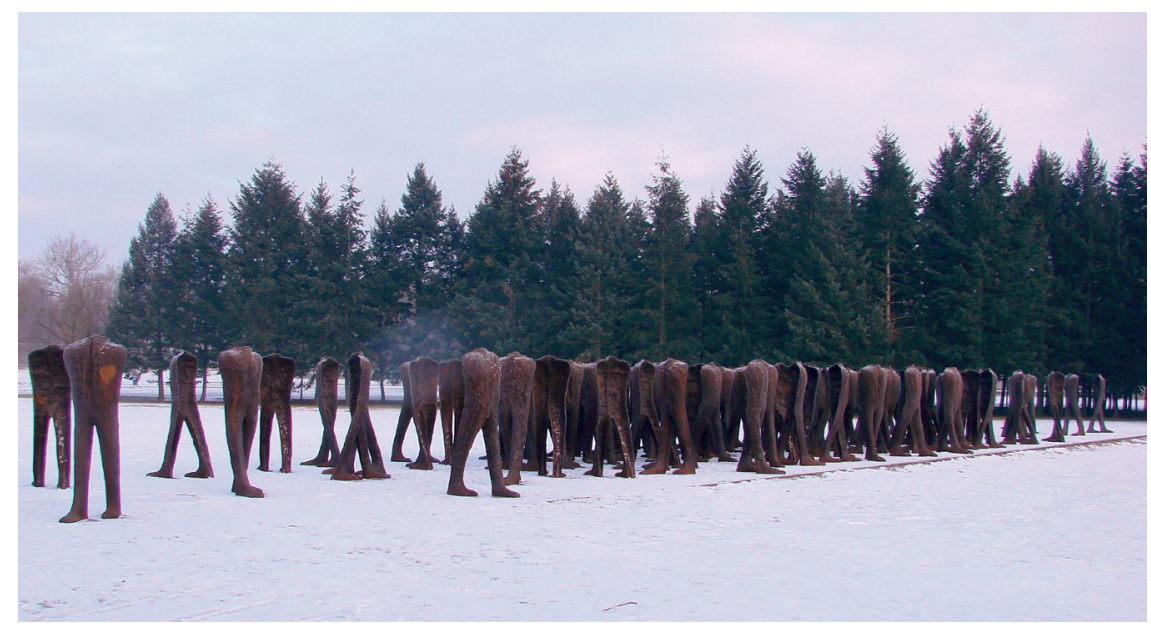

II. 3. Magdalena Abakanowicz, Nierozpoznani, żeliwo, 2002, Poznań, Park Cytadela (fot. J. Gernat 2016)

tragicznej ekspresji forma instalacji silnie przemawia do odbiorcy, szczególnie gdy doświadczymy jej polisensorycznie. Dzieło Abakanowicz widziane z dużej odległości już w pierwszych momentach oglądu uderza widza niepokojącym obrazem „wyrastających” z trawy ponurych bezgłowych, prawie identycznych sylwetek Nierozpoznanych, skupionych w tłumie, pozornie chaotycznym, zdezorganizowanym, w wielu miejscach sprawiającym jednak wrażenie muru nie do przebycia. Ów dramatyczny efekt ulega wzmocnieniu wraz ze stopniowym zbliżaniem się do rzeźby, kiedy to stają się coraz bardziej widoczne również cienie z tyłu postaci. Jednakże najsilniejszych emocji doznajemy dopiero w chwili, gdy wkraczamy w „tłum” (il. 4), zaczynając błądzić po labiryncie ścieżek pomiędzy kroczącymi humanoidami. Wówczas najbardziej uaktywniają się różne nasze zmysły: ruch, wzrok, dotyk, słuch, zapach. Za pomocą wzroku próbujemy ogarnąć przestrzeń sceny zaklętego w metalu „zdarzenia” - ciasną, miejscami nawet klaustrofobiczną w centralnym skupisku postaci, otwartą natomiast z boków w skrajnych punktach kompozycji, gdzie - zależnie od obranego przez nas kierunku przemieszczania się - tłum postaci zdaje się rozchodzić lub gęstnieć ku centrum, a tym samym następuje załagodzenie bądź stopniowe narastanie napięcia. Patrząc, obserwujemy również ekspresyjne, podobne do siebie wydrążone sylwetki Nierozpoznanych, wykonane w formie negatywowych odlewów, których nieregularna, chropowata powierzchnia - zarówno wewnątrz, jak i na zewnątrz - z bliska w pełni ujawnia dramatyczną grę światła i cienia, o nasileniu zmieniającym się zależnie od pory dnia. 
Równocześnie oprócz oglądania błądzące postaci możemy badać poprzez dotyk, dzięki któremu doświadczamy zróżnicowanej, w wielu miejscach jakby silnie pomarszczonej faktury figur i ich kształtów, opartych o ten sam uproszczony schemat bezgłowej sylwetki ludzkiej (o nieokreślonej płci), z zarysem stóp oraz klatki piersiowej - z przodu figur. Od tyłu, po negatywowej stronie odlewu, odnajdujemy natomiast zaznaczone $\mathrm{w}$ metalu podłużnymi wałkami ślady symbolicznych kręgosłupów postaci, których zróżnicowany „rysunek" ujawnia indywidualizm

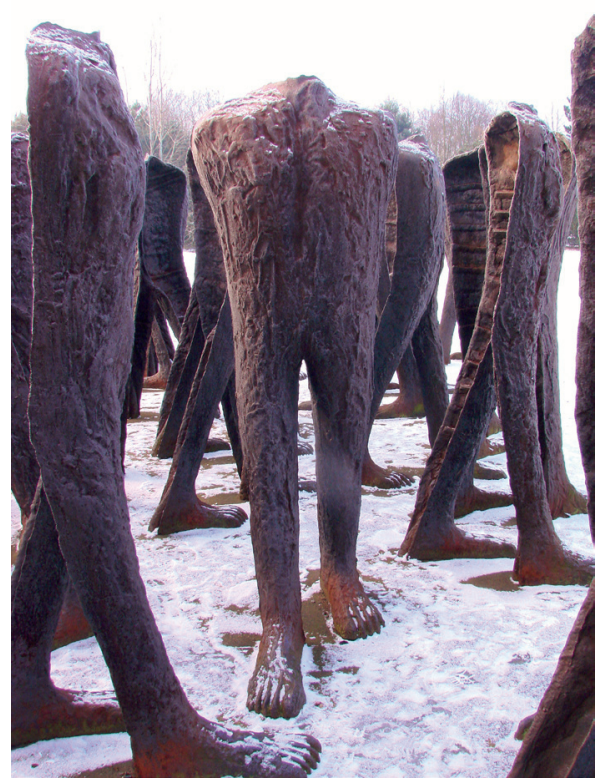

II. 4. Magdalena Abakanowicz, Nierozpoznani (fragment) każdego z pozornie identycznych

Nierozpoznanych. Także w tym wypadku dotykiem wyczuwamy ekspresję materiału - rdzawą powierzchnię pokrytego w większości patyną żeliwa, które zależnie od pogody może być zimne bądź nagrzane promieniami słońca, wilgotne po deszczu, nadto w różnych sytuacjach pogodowych może wydzielać określony zapach. Jeszcze inny wymiar doświadczania artystycznej kreacji Abakanowicz zyskujemy dzięki dźwiękom i wibracjom, towarzyszącym nam zwłaszcza gdy stąpamy po metalowej płycie. Odbiorca słyszy pogłos własnych kroków, najsilniej w centralnym punkcie kompozycji $\mathrm{z}$ racji maksymalnego skoncentrowania $\mathrm{w}$ tym miejscu figur rezonujących dźwięk. Dodatkowych wrażeń akustycznych dostarcza uderzenie powierzchni pojedynczej rzeźby; efekty dźwiękowe niekiedy potencjalnie wzmagać może również wiatr hulający pośród odlewów Nierozpoznanych, zlokalizowanych na otwartej przestrzeni parkowej polany.

Wszystkie te zmysłowe aspekty dzieła silnie oddziałują na odbiorcę, wywołując różnorodne emocje, zmuszając do zastanowienia. Forma rzeźbiarskiej instalacji może stwarzać w nim np. poczucie lęku, melancholii, traumy, zagubienia w psychodelicznej miejscami przestrzeni okupowanej przez anonimowe postaci jakby pozbawione ciała, interpretowane jako wyraz dramatycznej obecności człowieka we wszechwładnej przestrzeni politycznej 
260 i technicznej współczesnego świata ${ }^{16}$, zaś według słów samej autorki będące "znakiem wciąż trwającej obawy, konfrontacją z ilością i z sobą samym”"17. Może wzbudzać też inne uczucia, doznania estetyczne, nawet zachwyt powiedzmy rozmachem, oryginalnością czy głębią rzeźbiarskiej wizji, choć dzieło nie jest łatwe w zrozumieniu i nie dostarcza nam wprost kojącego doświadczenia piękna. Mimo to dostępność rzeźby w przestrzeni publicznej (dzięki omówionym walorom polisensorycznym również dla wielu niepełnosprawnych), siła artystycznego wyrazu oraz wyrafinowanie i oryginalność rzeźbiarskiej kreacji Abakanowicz, jej wieloznaczność otwierająca szerokie pole do różnych odczuć i interpretacji, zachęcają do wykorzystania pracy również jako medium arteterapeutycznego - np. jako środka wyzwalającego u terapeutyzowanych różne uczucia i nazywanie ich bądź też inspirującego do własnej kreatywności i twórczości.

Zaproponowana analiza różnych dzieł rzeźbiarskich wykazuje ogromną użyteczność z punktu widzenia historyka sztuki i wszelkiego innego edukatora zarówno wobec studentów niepełnosprawnych, jak i pełnosprawnych. Doświadczenie polisensorycznego kontaktu $\mathrm{z}$ dziełem pozwala bowiem odbiorcy na samodzielną „wędrówkę poznawczą", służącą odtworzeniu „historii” danej rzeźby, na którą się składa: dogłębne poznanie artystycznej formy pracy, jej materiał, technika wykonania, datowanie, ale także uchwycenie i zrozumienie stylistyki twórczości danego artysty rzeźbiarza. Co więcej, bezpośredni kontakt z dziełem uruchamia i rozwija procesy wyobraźni przestrzennej, dając w ten sposób każdej osobie możliwość wytworzenia własnego „wewnętrznego „ obrazu dzieła. W dalszej konsekwencji prowadzi to odkrywania jego symbolicznego znaczenia i nadania mu uniwersalnej rangi.

Tego rodzaju doświadczanie dzieła plastyki ma nie tylko walor poznawczo-edukacyjny, ale również terapeutyczny, ze względu na odczucia i reakcje, jakie praca rzeźbiarska może wywoływać u różnych grup odbiorców. W przypadku osoby niepełnosprawnej wzrokowo może to być np. radość, satysfakcja z poznania i poszerzenia swojego obrazu rzeczywistości o trzeci wymiar w tym szczególnym aspekcie, jakim jest sfera sztuki. Podobny potencjał ów sposób doświadczania rzeźby wykazuje wobec odbiorców sztuki o innych niepełnosprawnościach, np. dysfunkcyjnych słuchowo, niepełnosprawnych

16 [b. a.] Magdalena Abakanowicz „Nierozpoznani” - wystawa stała, http://culture.pl/pl/wyda rzenie/magdalena-abakanowicz-nierozpoznani-wystawa-stala (dostęp: 08.07.2014).

17 Magdalena Abakanowicz „Nierozpoznani” - wystawa stała, dz. cyt. 
intelektualnie, psychicznie lub osób z autyzmem. Doświadczenie polisensoryczne rzeźby może być atrakcyjne także dla osób pozbawionych na skutek różnych zahamowań kontaktu ze sobą, swoją psychiką lub swoim ciałem. Daje ono takiej osobie szansę na stopniowe otwarcie się na rzeczywistość, siebie samego, za pośrednictwem plastycznego medium. Siła i głębia przeżyć emocjonalnych są bowiem przede wszystkim wynikiem bezpośredniego doświadczenia. W ten naturalny sposób poprzez pogłębienie indywidualnych doznań następuje rozwój wrażliwości emocjonalnej i estetycznej człowieka.

Obiekt rzeźbiarski w ten sposób ma szansę stać się punktem wyjścia do rozmaitych warsztatów, zajęć o charakterze arteterapeutycznym, których istotnym elementem może być rozmowa uczestników - o sztuce, ale przede wszystkim o wrażeniach, odczuciach, emocjach, jakie wywołują odkrywane przez grupę dzieła, nazwaniu tych uczuć itp. - słowem, jak rzeźba na nas „działa”. Innym aspektem takich warsztatów może być własna aktywność twórcza uczestników - próba stworzenia własnej rzeźby z inspiracji wcześniejszymi „badaniami” określonych wytworów plastyki. W wypadku osób niepełnosprawnych wzrokowo proponowana w tym miejscu praktyka wydaje się zbliżona do opisanego przez Wandę Szuman procesu nauki przez niewidomych rysunku reliefowego. Jego podstawą jest zmysł dotyku, wspomagany doświadczeniem ruchowym, słuchowym, zapachowym czy smakowym, który pozwala rozpoznać określony przedmiot, odtwarzany następnie na papierze $\mathrm{w}$ postaci wytłaczanego rysunku ${ }^{18}$. Podobnie jak możliwość „terapii rzeźbą”, praktyka rysunku reliefowego poszerza wiedzę niewidomego o rzeczywistości, a zarazem aktywizuje go, często podnosząc jego poczucie własnej wartości ${ }^{19}$. Powracając do zagadnień związanych z rzeźbą, należy w tym miejscu raz jeszcze przywołać przykład programu edukacyjnego Muzeum Regionalnego w Stalowej Woli, którego propozycja tworzenia rzeźb z gliny inspirowanych Galerią przez dotyk stanowi szczególnie sugestywny i godny uwagi wzorzec, możliwy do wykorzystania również w warsztacie arteterapeutycznym. Uniwersalizm tego i wielu innych muzealnych pomysłów edukacyjnych sprawia, że kierować je można nie tylko do niepełnosprawnych wzrokowo, ale też do zróżnicowanych grup uczestników proponowanego przez autora warsztatu, zarówno niepełnosprawnych, jak i pozostałych.

18 W. Szuman, O dostępności rysunku dla dzieci niewidomych, Warszawa 1967, s. 16-26, 104-110.

19 W. Szuman, O dostępności..., dz. cyt., s. 124-130. 
Zarysowany problem rzeźby jako polisensorycznego medium edukacyjnego i terapeutycznego wymaga oczywiście szerszych i długoterminowych badań empirycznych z udziałem osób o różnych niepełnosprawnościach. Tym niemniej autor niniejszego szkicu ma nadzieję, że stanie się on przyczynkiem do podjęcia tego typu działań, do czego zachęca skuteczność programów realizowanych przez muzea sztuki, które - choć zorientowane na przybliżanie wytworów rzeźbiarzy poprzez nowatorskie ekspozycje i warsztaty edukacyjne głównie niepełnosprawnym - zyskują popularność również wśród pozostałych uczestników kultury. Możliwość zagospodarowania tej nowej relacji pomiędzy dziełem sztuki a odbiorcą przez arteterapię wskazuje z kolei na uniwersalizm i wielkie znaczenie tej dziedziny terapeutycznej, która opiera się na sztuce - w istocie jednego z najważniejszych i najbardziej skutecznych, wymyślonych przez człowieka „lekarzy dusz”.

\section{Sculpture as an educational and therapeutic medium for students with disabilities}

The article addresses the problem of therapeutic and cognitive functions of art, seen in the context of sculpture as an artistic medium accessible simultaneously through various perception channels (polysensory, or multisensory perception), which makes it particularly useful in art therapy aimed at diverse disabled and nondisabled audience. A sculpture is a spatial object, which renders it more accessible than other artworks to people with a range of dysfunctions, e.g. eyesight dysfunction; at the same time it encourages to appreciate it through other senses: touch, hearing, smell and sometimes even taste. This polysensory experience presents a cognitive advantage, compensating the blind for the dysfunctional sense, but also has a therapeutic value as it allows for an intensified aesthetic experience and offers the audience a completely new dimension of artistic experiences, which in turn benefits mental health.

The article discusses sculptures made using diverse materials in an attempt to show how the polysensory perception of figurative art may influence the audience, either nondisabled or disabled (particularly with vision impairment). These critical considerations allow to offer possible use of a sculptural works in education or art therapy, of both nondisabled and disabled students, with the aim of fostering social integration. The author provides also selected examples of art museum whose sculpture exhibition and education programmes may inspire similar solutions in academic teaching.

Keywords: sculpture, polisensory experience, art therapy, disfunction, accessibillity 
Artykuł podejmuje, na przykładzie analizy dzieł rzeźby wykonanej z różnych materiałów, próbę ukazania w jaki sposób polisensoryczny odbiór plastyki figuralnej może wpływać na odbiorcę, pełnosprawnego i dysfunkcyjnego (zwłaszcza niepełnosprawnego wzrokowo). Rozważania te pozwalają zaproponować możliwości wykorzystania dzieła rzeźbiarskiego w edukacji bądź arteterapii zarówno dla studentów niepełnosprawnych, jak i pełnosprawnych, celem integracji społecznej. Autor przywołuje również wybrane przykłady muzeów sztuki, których programy wystawiennicze i edukacyjne dotyczące rzeźby mogą być inspiracją dla wprowadzenia podobnych rozwiązań w nauczaniu akademickim.

Słowa kluczowe: rzeźba, doświadczenie polisensoryczne, arteterapia, dysfunkcja, dostępność

\section{Bibliografia}

Cuny Ch., Renouvellement de la Galerie tactile: „sculpter le corps”. Louvre. Communiqué de presse avril 2014, http://www.louvre.fr/sites/default/files/medias/medias_fichiers/ fichiers/pdf/louvre-cp-galerie-tactile.pdf (dostęp: 04.07.2014).

Cwalina T., Szlązak A., Warsztaty dla osób niewidomych i niedowidzących, [w:] Pakiet edukacyjny Dostępne Muzeum, red. E. Lisek, A. Szlązak, Stalowa Wola 2007.

Galeria przez dotyk. Edycja Il. Katalog poplenerowej wystawy rzeźby. Muzeum Regionalne w Stalowej Woli, pod red. M. Młynarskiego, A. Garbacz, Stalowa Wola 2008.

Gernat J., Doświadczenie polisensoryczne i jego znaczenie w edukacji artystycznej osób niepełnosprawnych, [w:] Edukacja i niepełnosprawność w wyobraźni socjopedagogicznej, Gorzów Wielkopolski 2013, s. 111-121.

Gernat J., Edukacja muzealna osób niepełnosprawnych i możliwość jej zastosowania w nauczaniu akademickim, [w:] Globalno-lokalne wyzwania uczelni wyższych zwiqzane z niepełnosprawnością, red. B. Orłowska, P. Prüfer, Gorzów Wielkopolski 2012, s. 137-146.

Gernat J., Terapia poprzez sztukę i jej znaczenie dla zdrowego trybu życia oraz integracji studentów niepełnosprawnych, [w:] Promocja zdrowia w chorobie i niepełnosprawności. Modele zdrowego stylu życia jako wyzwanie współczesnych uczelni wyższych, Gorzów Wielkopolski 2014, s. 135-140.

Gogol W., Świat poprzez sztukę dotyku staje się bardziej dostępny, [w:] Galeria przez dotyk. Edycja II. Katalog poplenerowej wystawy rzeźby. Muzeum Regionalne w Stalowej Woli, pod red. M. Młynarskiego, A. Garbacz, Stalowa Wola 2008, s. 20-22.

Kalinowski K., Rzeźba barokowa na Śląsku, Warszawa 1986. 
Karga M., Co to jest SI, http://www.integracjasensoryczna.com.pl/pl/Co-to-jest-SI (dostęp: 18.06.2015).

[b. a.] Magdalena Abakanowicz "Nierozpoznani” - wystawa stała, http://culture.pl/pl/ wydarzenie/magdalena-abakanowicz-nierozpoznani-wystawa-stala (dostęp: 08.07.2014).

Nowak R., Michat Klahr Starszy i jego theatrum sacrum, Kłodzko 1992.

Pajek J., Kamienne wtajemniczenie, [w:] Galeria przez dotyk. Edycja Il. Katalog poplenerowej wystawy rzeźby. Muzeum Regionalne w Stalowej Woli, pod red. M. Młynarskiego, A. Garbacz, Stalowa Wola 2008, s. 11-13.

Słownik terminologiczny sztuk pięknych, pod red. K. Kubalskiej-Sulkiewicz, M. Bielskiej-Łach, A. Manteuffel-Szaroty, wyd. 5, Warszawa 2006.

Szeląg M., Pozwalamy dotykać! Muzea wobec potrzeb różnorodnej publiczności, [w:] 5 zmysłów. Audiodeskrypcja, pod red. E. Drążkowskiej, M. Szeląga, Poznań 2011, s. 15-23.

Szuman W., O dostępności rysunku dla dzieci niewidomych, Warszawa 1967.

Muzeum Narodowe w Krakowie - informacja dotycząca działań na rzecz osób niepełnosprawnych w latach 2008-2012, mps.

Teatr i mistyka. Rzeźba barokowa pomiędzy Zachodem a Wschodem, pod red. K. Kalinowskiego, Poznań 1993.

Woydyłło E., Psychoterapeutyczna funkcja sztuki w świecie postindustrialnym, http:// www.woydyllo.pl/ (dostęp: 13.03.2014).

Żuchowski T. J., Poskromienie materii. Nowożytne zmagania rzeźbiarzy z marmurem kararyjskim. Michał Anioł, Bernini, Canova, Poznań 2011.

http://culture.pl (dostęp: 04.07.2014).

http://www.integracjasensoryczna.com.pl (dostęp: 04.07.2014).

http://www.louvre.fr (dostęp: 04.07.2014).

http://muzeum. stalowawola.pl (dostęp: 04.07.2014).

http://www.woydyllo.pl (dostęp: 04.07.2014). 